\title{
The effects of autonomy support on salivary alpha-amylase: The role of individual differences
}

\author{
Vanda Sieber $^{\mathrm{a}, *}$, Julia Schüler ${ }^{\mathrm{b}}$, Mirko Wegner ${ }^{\mathrm{c}}$ \\ a University of Zurich, Switzerland \\ ${ }^{\mathrm{b}}$ University of Konstanz, Germany \\ c University of Bern, Switzerland
}

\begin{abstract}
A B S T R A C T
The empirical evidence for the relationship between autonomy-supportive environments and physiological stress is inconsistent. Whereas some studies report a decrease in stress in autonomy-supportive environments, other studies show a negative effect of autonomy on physiological stress. As previous research has not considered individual differences within this relationship, the present research aims to close this empirical gap by proposing that an implicit autonomy disposition, which is defined as a dispositional preference for self-determination, serves as a moderator. In an experiment, we tested whether the autonomy disposition moderates the effect of different teaching styles (controlling, autonomy-supportive, and neutral) on the acute physiological stress response (salivary alpha-amylase) in adolescents $(N=69)$. The study revealed that participants with a high implicit autonomy disposition displayed lower salivary alpha-amylase responses when exposed to autonomy-supportive vignettes compared to when they were exposed to controlling or neutral teaching styles. The opposite pattern was found in students with a low implicit autonomy disposition. The results illustrate that experimentally induced variations in autonomy support lead to different physiological stress responses, depending on individual differences in the implicit autonomy disposition.
\end{abstract}

\section{Introduction}

Several situations in everyday life can lead to psychosocial stress, which is known to be reflected in physiological processes and can constitute a serious health risk (Dickerson and Kemeny, 2004). One important aspect affecting stress in everyday situations is the behavior of persons in higher hierarchical positions, such as superiors in the work context (Nie et al., 2015) or teachers at school (Reeve and Tseng, 2011). Previous studies have convincingly shown that autonomy support has beneficial effects on different facets of well-being such as vitality and life satisfaction across different contexts (Adie et al., 2008; Levesque et al., 2004; Patrick et al., 2000). However, there are also studies showing that autonomy, such as the possibility to make choices, may decrease psychological well-being (Grant and Schwartz, 2011; Schwartz, 2000; Schwartz and Ward, 2004). There are fewer studies testing the relationship between autonomy support and physiological stress. The existing studies

\footnotetext{
* Corresponding author.

E-mail address: sieber@psychologie.uzh.ch (V.Sieber).
}

on this link (Reeve and Tseng, 2011; O'Donnell et al., 2015) have revealed inconsistencies and it is not clear whether autonomy is associated with an increase or a decrease in physiological stress. In a school context, Reeve and Tseng (2011) were able to identify effects of teachers' autonomy support on students' cortisol levels. Applying reasoning from self-determination theory (Deci and Ryan, 1985,2000 ), which states that people benefit from autonomy support Reeve and Tseng (2011), found that children confronted with a controlling teacher displayed higher physiological stress during a learning activity than children confronted with an autonomysupportive teacher. The school context is of particular importance for the present study because autonomy has been previously shown to positively affect areas that are relevant for children's psychological well-being (Ryan and Grolnick, 1986), motivation (Reeve et al., 2004), and performance in school (Black and Deci, 2000).

In contrast to this evidence for the positive stress-reducing effect of autonomy-supportive environments, a different study illustrated that autonomy can also elevate stress. A recently published study by O'Donnell et al. (2015) found that people displayed a higher physiological stress response, as reflected in their heart rate variability, heart rate, and salivary alpha-amylase, when given the opportunity 
to choose the timing of their breaks during a word processing task in a simulated office environment.

Even applying the necessary amount of caution when comparing these studies (different setting, different samples, and different indicators for physiological stress), they reveal a certain inconsistency about the effect of autonomy-supportive social environments on physiological stress responses. Considering the vast literature on the impact of autonomy-supportive social environments in the school context on different aspects of well-being and motivation (Ryan and Grolnick, 1986; Reeve et al., 2004; Black and Deci, 2000), the present study examines the effect of autonomy-supportive social environments in a school context, more precise in physical education. This setting is considered as particularly important, as positive experiences in physical education classes are seen as an important aspect contributing to a more active life-style and therefore can contribute to a healthier life (Hagger et al., 2003). Moreover, the present research suggests an autonomy disposition as a moderating variable.

The autonomy disposition is defined as a stable concern to experience psychological freedom and the endeavor to feel oneself to be the acting agent across different situations (DeCharms, 1968; Schüler et al., 2014). Like other implicit dispositions, which have been shown to affect physiological stress responses (Wegner et al., 2014), the implicit autonomy disposition is assumed to reflect nonconscious and affect-based preferences for certain incentives (e.g. feeling autonomous) (Schüler et al., 2014). In two studies, Schüler et al. (2014) found that autonomy support was especially beneficial in terms of motivation and well-being for people with a moderate to high implicit autonomy disposition but not for people with a low implicit autonomy disposition. This result fully confirms a "matching hypothesis" (e.g. Hofer and Busch, 2011; Schüler et al., 2013; Schüler et al., 2010; Sheldon and Schüler, 2011), according to which individuals benefit if their personality (e.g., achievement motive, autonomy disposition) fits their social environment (e.g., opportunity for experiences of competence or autonomy, respectively). However, the existing work on the matching hypothesis has so far not analyzed the effects on stress. The present research fills this gap by testing the hypothesis that the implicit autonomy disposition moderates the effects of an autonomy-supportive environment on physiological stress. To be more specific, we analyzed whether experimentally-induced autonomy support in a school sport context produces different effects on salivary alpha-amylase (SAA) levels in school children with high and low autonomy dispositions.

By testing this moderator hypothesis, we aim to clarify how autonomy-supportive environments affect physiological stress reactions in a school context. We designed an experiment in which adolescents' physiological short-term reaction to an autonomysupportive or autonomy-restrictive sport teacher was examined. In contrast to long-term reactions to stress, which are reliably measured by cortisol - that being the principal hormone of the hypothalamic-pituitary-adrenal axis (HPA) (Ali and Pruessner, 2012; Chrousos, 2009) - short-term and fast stress responses (Skoluda et al., 2015) are more strongly represented by the activity of the sympathetic nervous system(SNS). The response of the SNS is very quick: it activates pre-ganglionic sympathetic nerves, located in the locus coeruleus. This mechanism triggers the release of norepinephrine and epinephrine from the adrenal medulla, which in turn triggers several peripheral reactions, such as an increase in salivary alpha-amylase (SAA), heart rate, and blood pressure, which can be measured relatively promptly after the onset of the stressor (Ali and Pruessner, 2012; Chrousos, 2009; Nater and Rohleder, 2009). In recent research, sAA has been shown to reliably reflect the short-term reaction to different stressors in experimental situations (Allwood et al., 2011; Nater et al., 2005; Nater and Rohleder, 2009; van Stegeren et al., 2006; Skoluda et al., 2015).

\section{Methods}

\subsection{Participants}

Sixty-nine students ( 34 females. $^{1}$ ) aged between 12 and 16 years $(M=14.16, S D=1.30)$ participated in the experimental study, which took place on a regular school day. The participants were recruited in high schools in the German-speaking part of Switzerland and the sample was primarily Caucasian ( $N=63$; Swiss African: $N=3$, Swiss Hispanics: $N=3$ ). Participation was on a voluntary basis. Participants and their parents signed an informed consent form prior to participation. The present study was approved by the ethics committee of the Faculty of Human Sciences at the University of Bern, Switzerland and is in accordance with the Declaration of Helsinki.

\subsection{Design and procedure}

The experiment was conducted in a regular school setting. Sixty participants were tested in the afternoon and nine participants were tested in the morning. The participants first completed the Picture Story Exercise in order to assess their implicit autonomy disposition. Afterwards, participants gave the first saliva sample, so as to determine their baseline sAA. In order to obtain unbiased samples, the participants rinsed their mouths with water and were not allowed to talk while the saliva samples were taken. Additionally, they were not allowed to consume nicotine or caffeine, eat or drink for at least one hour before the saliva sampling. After the saliva sample had been taken, they read the general instructions for the experimental manipulation and were randomly assigned to either an autonomy-supportive (AS, $n=27$ ), an autonomy-restrictive (AR, $n=22)$, or a control group (CG, $n=20$ ). In both experimental groups (AS and AR), participants were asked to project their thoughts into a set of seven scenarios in which they had to interact with either an autonomy-supportive or a controlling sports teacher (for a similar procedure see Schüler et al., 2014). Participants were asked to vividly imagine the scenarios, visualize them, and focus on their thoughts and emotions. The scenarios were formulated following the items from the Health Climate Questionnaire (Williams et al., 1996) which were adapted to the sport context (e.g., "I feel that my coach provides me with choices and options"). To facilitate the subject's imagination, the items were embedded into a typical scene of a physical education lesson in school. In the AS group, participants read scenarios like: "Your physical education teacher explains that there are different ways to carry out an exercise and lets you choose the way you want to do it." People in the autonomyrestrictive group received a similar scenario, where the behavior of the teacher was changed into autonomy-restrictive behavior, an example being: "Your sports teacher takes a decision without giving a rationale and determines the way you have to carry out the exercise." Meanwhile the control group was instructed to read the description of a sport hall. After the 10-min vignette exercise, the participants were asked to give a second sAA sample. After sample collection, the participants answered questions concerning medical issues, medication (including contraceptives), substance abuse (e.g. smoking, cannabis consumption), caffeine consumption, as well as sleeping habits. ${ }^{2}$ After the completion of the questionnaire, the participants were debriefed about the study's aims, and written information was provided including contact details of the responsible persons of the study.

\footnotetext{
1 None of the female participants were on birth control.

2 The survey contained other variables that were collected to answer research questions not related to the present one.
} 
Table 1

Summary of hierarchical regression analysis for variables predicting post-test sAA, with 95\% bias corrected and accelerated confidence intervals reported in parentheses. Confidence intervals and standard errors based on 1000 bootstrap samples.

\begin{tabular}{|c|c|c|c|c|c|c|c|c|c|}
\hline \multirow[t]{2}{*}{ Variable } & \multicolumn{3}{|c|}{ Model 1} & \multicolumn{3}{|l|}{ Model 2} & \multicolumn{3}{|l|}{ Model 3} \\
\hline & $B$ & $S E B$ & $p$ & $B$ & $S E B$ & $p$ & $B$ & $S E B$ & $p$ \\
\hline Time at sampling & 0.367 & 0.195 & 0.061 & 0.374 & 0.206 & 0.066 & 0.433 & 0.217 & 0.047 \\
\hline Baseline SAA & 2.851 & 0.240 & 0.001 & 2.864 & 0.264 & 0.004 & 2.835 & 0.261 & 0.001 \\
\hline \multicolumn{10}{|l|}{ Experimental Group } \\
\hline AR-dummy & & & & -0.184 & 0.642 & 0.770 & -0.010 & 0.651 & 0.989 \\
\hline CG-dummy & & & & -0.255 & 0.575 & 0.673 & -0.395 & 0.553 & 0.493 \\
\hline Autonomy disposition (Aut) & & & & 0.045 & 0.219 & 0.840 & -0.522 & 0.342 & 0.138 \\
\hline \multicolumn{10}{|l|}{ Experimental group $\times$ Aut } \\
\hline AR-dummy $\times$ Aut & & & & & & & 1.372 & 0.684 & 0.046 \\
\hline CG-dummy $\times$ Aut & & & & & & & 0.956 & 0.444 & 0.037 \\
\hline
\end{tabular}

Note: AR: autonomy restriction group, AS: autonomy support group, CG: control group, AR-dummy (AS: 0, AR: 1, CG: 0), CG-dummy (AS: 0, AR: 0, CG: 1).

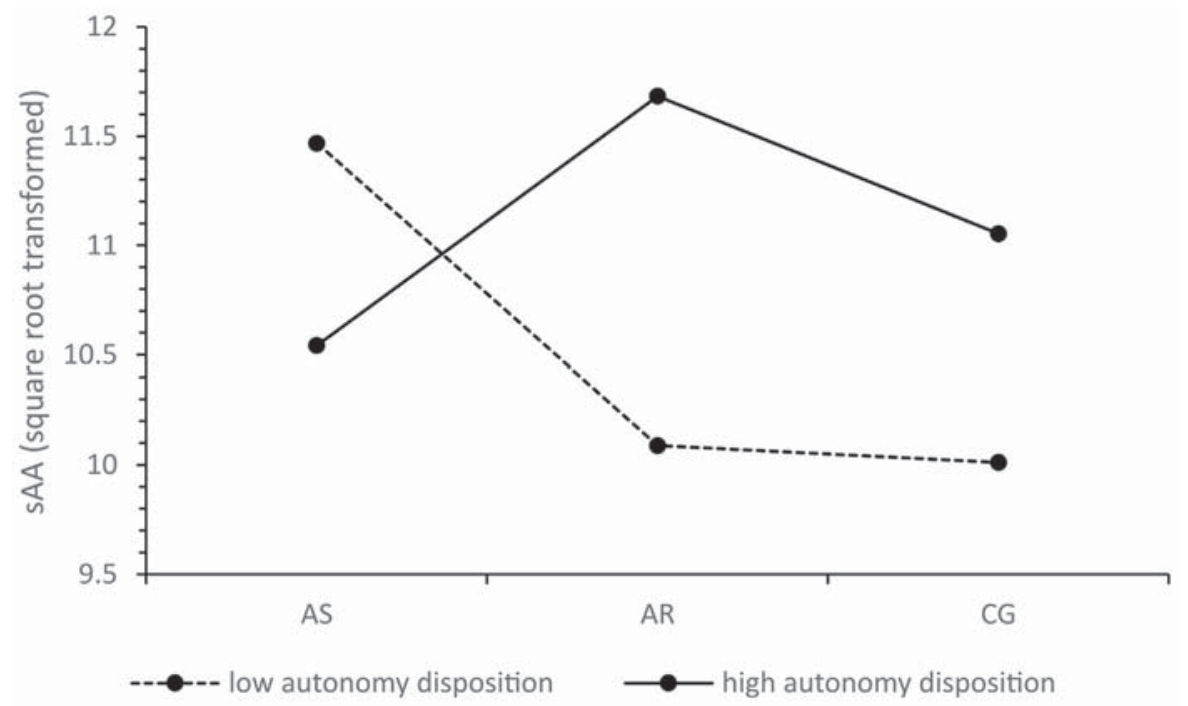

Fig. 1. Effect of experimental manipulation $(A S=$ autonomy support, $A R=$ autonomy restriction, $C G=$ control group $) \times$ implicit autonomy disposition interaction on square root transformed sAA (salivary alpha-amylase).

\subsection{Materials}

\subsubsection{Implicit autonomy disposition}

The implicit autonomy disposition was assessed using the Picture Story Exercise (PSE, Schultheiss and Pang, 2007; Murray, 1943). In the present study, participants were asked to write imaginative stories about four standard pictures (stimulus material: women in a laboratory, ship's captain, trapeze artists, and boxer). The participants were instructed to look at the picture for $15 \mathrm{~s}$ and then write a story about the picture for four minutes. We analyzed the stories using scoring categories from DeCharms and Plimpton (1992); for a similar procedure see Schüler et al., 2014). Autonomy was coded when one of the following categories was mentioned in the stories: (a) self-determined goal setting, (b) instrumental activities to reach the goal, (c) reality perception, (d) personal responsibility, (e) self-confidence, and (f) personal causation. Two experienced raters coded the stories. Their inter-rater reliability (ICC) was 0.94 . Scoring disagreements were discussed and resolved in additional sessions. Autonomy scores ranged from 0 to $15(M=6.36, S D=3.79)$. For subsequent analyses, the scores were corrected for word count (range from 82 to 333 words), as they were correlated (as recommended by Schultheiss and Pang, 2007). Following the guidelines given by Schultheiss and Pang (2007), we used regression analysis to residualize the implicit motive scores for word count and used the residual scores in the analyses reported below.

\subsubsection{Salivary alpha-amylase}

Salivary alpha-amylase $(\mathrm{U} / \mathrm{ml})$ was assessed by letting participants passively drool $10 \mathrm{ml}$ of saliva into sampling tubes using SaliCaps ${ }^{\circledR}$ (IBL International, Hamburg, Germany). SaliCaps have been previously used successfully to assess SAA in different studies (for this procedure, see also Schoofs and Wolf, 2009; Sumter et al., 2010). After collection, the samples were stored at $-20^{\circ} \mathrm{C}$ until analysis (see Rohleder et al., 2004; Strahler, 2012). A chemiluminescence immunoassay procedure (IBL, Hamburg, Germany) was applied to assess sAA levels in the samples. The intra- and inter-assay coefficients for the raw SAA scores were below $3 \%$. As the raw SAA measures were substantially skewed for the baseline (skew $=1.18, S E=0.29$ ) as well as for the post-test scores (skew $=0.90, S E=0.29$ ), a square root transformation was carried out (transformed skew baseline $=0.38, S E=0.29$, transformed skew post-test $=0.28, S E=0.29$ ), in order to obtain a normal distribution (for this procedure, see also Granger et al., 2007). Additionally, the scores were $\mathrm{z}$-transformed in order to conduct the moderation analysis.

\section{Results}

\subsection{Preliminary analyses and descriptive statistics}

In preliminary analyses we found that the three experimental groups did not differ regarding their baseline sAA 
scores (AS: $M=100.07, S D=75.84 ; A R: M=96.09, S D=53.41 ; C G$ : $M=145.91 ; S D=99.30), F(2,68)=2.695, p=0.08$. Correlational analyses revealed that SAA was not associated with the participants' age, $r=-0.03, p=0.79$. Additionally, no significant differences in baseline sAA levels were found between people assessed in the morning and in the afternoon, $t(9)=-0.83, p=0.43$, as well as for gender, $t$ $(66)=1.08, p=0.27^{3}$. But the time of sampling was associated with the dependent measure of sAA, $r=0.29, p=0.02$, and is therefore included in further analyses as a control variable.

\subsection{Moderation analysis}

In order to test the moderating effect of the implicit autonomy disposition on SAA responses in the three experimental groups, a hierarchical regression analysis was conducted in three steps (see Table 1). In the first model, we controlled for the baseline sAA scores, as well as for the time of testing (z-transformed). The second model included the experimental manipulation (AS, AR, CG) and the moderator (implicit autonomy disposition). In the third model, the interaction between the implicit motive and the experimental conditions was added. In order to test the interaction between the three experimental groups (AS, AR, CG) and autonomy disposition, the two dummy variables AR-dummy (coded 1 for AR, 0 for AS and 0 for CG) and CG-dummy (coded 0 for AS, 0 for AR und 1 for CG) were created. The interaction terms (Model 3) were significant for AR-dummy $\times$ autonomy disposition, $b=1.37, s e_{\mathrm{b}}=0.68$, $p=0.046,95 \% \mathrm{BCa} C \mathrm{CI}[0.230,2.962]$ and for CG-dummy $\times$ autonomy disposition, $b=0.96, s e_{\mathrm{b}}=0.44, p=0.037,95 \% \mathrm{BCa}$ CI $[0.100,1.897]{ }^{4}$ The nature of this interaction is depicted in Fig. 1; people with a high implicit autonomy disposition display the highest sAA scores when they are exposed to an autonomy-restrictive physical education teacher, compared with an autonomy-supportive physical education teacher. In the control group, people with a high implicit autonomy disposition display higher sAA scores than those in the autonomy-supportive group. In contrast, people with a low implicit autonomy disposition had lower sAA levels in an autonomy-restrictive setting, as well as in the control group, but higher sAA levels in the autonomy supportive group.

\section{Discussion}

Past research examining physiological stress responses to experimental variations in autonomy has produced inconsistent results, some finding positive and others negative relationships. The present study proposes an individual differentiating variable, the implicit autonomy disposition, as an important moderator of the effect of autonomy support on salivary alpha-amylase. The results of the regression analysis illustrate that experimentally induced variations in autonomy support provided by the environment (autonomy-supportive vs. autonomy-restrictive behavior of a physical education teacher vs. neutral description of a gym) lead to different physiological stress responses as reflected by sAA,

\footnotetext{
3 Additionally gender was not found to be a moderator of the interaction effect in the main analysis, AR-dummy $\times$ autonomy disposition $\times$ gender, $b=1.81, s e_{\mathrm{b}}=1.43$, $p=0.79,95 \%[-2.069,2.710]$; CG-dummy $\times$ autonomy disposition $\times$ gender, $b=0.32$, $s e_{\mathrm{b}}=1.92, p=0.22,95 \%[-1.142,4.761]$.

${ }^{4}$ The inspection of total word count indicates that four participants wrote stories which were shorter than 30 words, which recurrently is considered as a threshold for coding motive imagery (c.f. Walker and Atkinson, 1958; Hofer and Busch, 2011). Running the regression without those participants does not change the interaction pattern (AR-dummy $\times$ autonomy disposition, $b=1.35$, $s e_{\mathrm{b}}=0.69, p=0.045,95 \% \mathrm{BCa}$ $\mathrm{CI}[0.185,2.886])$. However, the analysis for the comparison between the control group and the autonomy supportive group was weaker, and did not reach significance, CG-dummy $\times$ autonomy disposition, $b=0.78, s e_{\mathrm{b}}=0.47, p=0.09,95 \% \mathrm{BCa} \mathrm{Cl}$ $[-0.134,1.703]$
}

depending on individual differences in the implicit autonomy disposition.

Taking a closer look at the interaction pattern (see Fig. 1) shows that people with a high implicit autonomy disposition in the autonomy-restrictive group display higher sAA scores, indicating higher levels of stress, compared with people with a high implicit autonomy disposition in the autonomy-supportive group and those in the control group. For people with a low implicit autonomy disposition, the interaction pattern is reversed: people with a low implicit autonomy disposition in the autonomy-supportive group display the highest sAA scores compared with the other two experimental groups (control group and autonomy restriction).

This result is in line with the existing empirical evidence from the matching hypothesis proposed by Schüler et al. $(2013,2014)$, which states that people differ in how they react to autonomy support provided by the environment depending on their implicit autonomy disposition. This study contributes to these findings by showing that a fit between disposition and environment leads to decreased salivary alpha-amylase levels whereas a mismatch between these variables leads to increased levels. Thus, for the first time, a physiological stress response has been shown to be dependent on the disposition-environment interaction.

This finding is of high theoretical relevance, as it provides an insight into how autonomy affects physiological stress. Moreover, it can be seen as a first step to explaining why different studies came to diverging conclusions concerning the impact of autonomy on physiological stress (O'Donnell et al., 2015; Reeve and Tseng, 2011). Additionally, our results have a high practical relevance, as they suggest that the implicit autonomy disposition - as a moderator of the link between autonomy support and physiological stress - is an important factor to consider when designing health-promoting school environments.

\section{Limitations and further directions}

Whereas the present study focused on a short-term physiological stress reaction, future research is strongly encouraged to assess whether a mismatch between the implicit autonomy disposition and long-lasting autonomy support from the environment can lead to chronic stress, which can be measured with long-term stress indicators, such as cortisol. In order to analyze long-term stress reactions, thoroughly controlled field experiments are needed, in which for example a teacher's or a coach's autonomy-supportive behavior is altered over a longer intervention period of several weeks. Additionally, future research might want to add further short-term stress indicators of the ANS, such as heart rate, heart rate variability, or skin conductance, in order to confirm our findings with sAA. Moreover, if applicable, future research should standardize time of sampling, which would be of additional importance when analyzing cortisol known to be sensitive to diurnal variations (Dickerson and Kemeny, 2004).

One of the strengths of the present study is that it examines sAA responses in a young sample aged between 12 and 16 years, adding to the scarce research base in this age group. However, previous research comparing sAA responses in different age groups suggested that children and older adults show attenuated response patterns (Strahler et al., 2010). Studies also suggested that differences in pubertal status might be associated with sAA responses to social evaluative psychological stressors such as the Leiden Public Speaking Task (see van den Bos et al., 2014) or peer rejection (Stroud et al., 2009). Even if the task in the present study did not directly involve social evaluation, it would be interesting for future research to include an objective measure of pubertal status in addition to the assessment of participants' age. This could be done by a self-report questionnaire such as the pubertal development scale 
(Petersen et al., 1988) or if applicable, through a physical examination by a trained clinician which is considered best practice by many researchers (see van den Bos et al., 2014).

Although the vignette method has several strengths, such as minimizing the effects of physical activity on the physiological measure sAA (see for example Nater and Rohleder, 2009), future research might also test the relationship examined here in a reallife setting, in order to strengthen the generalizability of the results. Additionally, future studies employing vignettes could improve the methodological procedure by for example testing whether individuals differ in their abilities to imagine the scenarios, and whether this influences the reported results. One limitation of the present study is that we did not measure how much autonomy support the participants experienced. This was due to the fact, that we used a questionnaire which is usually used to measure autonomy support (Williams et al., 1996) to design the vignettes. Employing such a manipulation check was considered as redundant information. In order to avoid administering redundant information to the participants, future research might for example use a visual analog scale with anchor words related to autonomy support (e.g., "I could act completely self-determined" versus "I felt controlled") in order to provide a manipulation check.

Future research may also focus on different settings, such as work environments, health settings, and other educational settings (universities). More research is also needed to examine the differential effect of established leadership styles, such as transformational leadership, which is known to foster the satisfaction of basic psychological needs and support a person's self-determination (Kovjanic et al., 2012).

Additionally, future research might focus on mechanisms underlying the negative effect of autonomy supportive environments for people with a low implicit autonomy disposition. Following the rationale of previous research, studies could assess whether the heightened stress response in people with a low implicit disposition is due to more difficulties in goal striving in domains that target the specific disposition they are low in (see Schultheiss and Köllner, 2014). Autonomy supportive environments therefore might act as a stressor for people with a low implicit autonomy disposition, and might lead to effortful goal-pursuit and low motive-driven hedonic response. Moreover, autonomy supportive environments could also act as disincentive (Schultheiss, 2008) for other implicit motives (such as affiliation or achievement) for people with a low autonomy disposition. As a consequence, the disincentive could act as stressor to their dominant implicit motive (Schultheiss and Köllner, 2014).

\section{Conflicts of interest}

The authors have no conflicts of interest and declare nonfinancial interests. All authors disclose any actual or potential conflict of interest including any financial, personal or other relationships with other people or organizations that could inappropriately influence, or be perceived to influence, their work.

\section{Contributors}

All authors were involved in the conception and design of the study. The acquisition and analysis of the data was mainly conducted by VS. VS wrote the first draft of the manuscript. JS and MW made substantial contributions to the first draft, by revising it critically. All authors contributed and have approved the final manuscript.

\section{Role of the funding source}

This work was supported by funds from the Federal Office of Sports in Switzerland (Grant NR 37-203). Saliva sampling was funded by research funding of the University of Bern, Switzerland (31-375). Both funding sources had no further role in the study design; collection, analysis, and interpretation of data; in writing the report; or in the decision to submit the paper for publication.

\section{Acknowledgements}

Vanda Sieber is supported by the Federal Office for Sport in Switzerland (Bundesamt für Sport). Additionally we would like to thank Manuela Engel and Samantha Gerber for their support in data collection.

\section{References}

Adie, J., Duda, J.L., Ntoumanis, N., 2008. Autonomy support, basic need satisfaction and the optimal functioning of adult male and female sport participants: a test of basic needs theory. Motiv. Emot. 32, 189-199, http://dx.doi.org/10.1007/ s11031-008-9095-Z.

Ali, N., Pruessner, J.C., 2012. The salivary alpha amylase over cortisol ratio as a marker to assess dysregulations of the stress systems. Physiol. Behav. 106 (1), 65-72, http://dx.doi.org/10.1016/j.physbeh.2011.10.003.

Allwood, M.A., Handwerger, K., Kivlighan, K.T., Granger, D.A., Stroud, L.R., 2011. Direct and moderating links of salivary alpha-amylase and cortisol stress-reactivity to youth behavioral and emotional adjustment. Biol. Psychol. 88 (1), 57-64, http://dx.doi.org/10.1016/j.biopsycho.2011.06.008.

Black, A.E., Deci, E.L., 2000. The effects of instructors' autonomy support and students' autonomous motivation on learning organic chemistry: a self-determination theory perspective. Sci. Educ. 84 (6), 740-756.

Chrousos, G.P., 2009. Stress and disorders of the stress system. Nat. Rev. Endocrinol. 5 (7), 374-381.

DeCharms, R., Plimpton, F., 1992. The origin scoring system. In: Smith, C.R. (Ed.), Motivation and Personality: Handbook of Thematic Content Analysis. Cambridge University Press, Cambridge, pp. 334-375.

DeCharms, R., 1968. Personal Causation. Academic Press, New York.

Deci, E.L., Ryan, R.M., 1985. Intrinsic Motivation and Self-Determination in Human Behaviour. Plenum, New York.

Deci, E.L., Ryan, R.M., 2000. The what and why of goal pursuits: human needs and the self-determination of behavior. Psychol. Inq. 11 (4), 227-268.

Dickerson, S.S., Kemeny, M.E., 2004. Acute stressors and cortisol responses: a theoretical integration and synthesis of laboratory research. Psychol. Bull. 130 (3), 355-391, http://dx.doi.org/10.1037/0033-2909.130.3.355.

Granger, D.A., Kivlighan, K.T., El-Sheikh, M., Gordis, E.B., Stroud, L.R., 2007. Salivary-amylase in biobehavioral research: recent developments and applications. Ann. N. Y. Acad. Sci. 1098 (1), 122-144, http://dx.doi.org/10.1196/ annals.1384.008.

Grant, A.M., Schwartz, B., 2011. Too much of a good thing: the challenge and opportunity of the inverted U. perspect. Psychol. Sci. 6 (1), 61-76, http://dx. doi.org/10.1177/1745691610393523.

Hagger, M.S., Chatzisarantis, Nikos L.D., Culverhouse, T., Biddle, Stuart J.H., 2003. The processes by which perceived autonomy support in physical education promotes leisure-time physical activity intentions and behavior: a trans-contextual model. J. Educ. Psychol. 95 (4), 784-795, http://dx.doi.org/10. 1037/0022-0663.95.4.784.

Hofer, J., Busch, H., 2011. Satisfying one's needs for competence and relatedness: consequent domain-specific well-being depends on strength of implicit motives. Pers. Soc. Psychol. B 37 (9), 1147-1158, http://dx.doi.org/10.1177/ 0146167211408329.

Kovjanic, S., Schuh, S.C., Jonas, K., van Quaquebeke, N., van Dick, R., 2012. How do transformational leaders foster positive employee outcomes? A self-determination-based analysis of employees' needs as mediating links. J. Organiz. Behav. 33 (8), 1031-1052, http://dx.doi.org/10.1002/job.1771.

Levesque, C., Zuehlke, A.N., Stanek, L.R., Ryan, R.M., 2004. Autonomy and competence in German and American University students: a comparative study based on self-determination theory. J. Educ. Psychol. 96 (1), 68-84, http://dx.doi.org/10.1037/0022-0663.96.1.68.

Murray, H.A., 1943. Thematic Apperception Test. Harvard University Press, Cambridge, MA.

Nater, U.M., Rohleder, N., 2009. Salivary alpha-amylase as a non-invasive biomarker for the sympathetic nervous system: current state of research. Psychoneuroendocrinology 34 (4), 486-496, http://dx.doi.org/10.1016/j. psyneuen.2009.01.014.

Nater, U.M., Rohleder, N., Gaab, J., Berger, S., Jud, A., Kirschbaum, C., Ehlert, U. 2005. Human salivary alpha-amylase reactivity in a psychosocial stress paradigm. Int. J. Psychophysiol. 55 (3), 333-342, http://dx.doi.org/10.1016/j. ijpsycho.2004.09.009. 
Nie, Y. Chua, B.L. Yeung A.S. Ryan, R.M., Chan, W.Y, 2015. The importance of autonomy support and the mediating role of work motivation for well-being: testing self-determination theory in a Chinese work organisation. Int. J. Psychol. 50 (4), 245-255, http://dx.doi.org/10.1002/ijop.12110.

O’Donnell, E., Landolt, K., Hazi, A., Dragano, N., Wright, B.J., 2015. An experimental study of the job demand-control model with measures of heart rate variability and salivary alpha-amylase: evidence of increased stress responses to increased break autonomy. Psychoneuroendocrinology 51, 24-34, http://dx. doi.org/10.1016/j.psyneuen.2014.09.017.

Patrick, B.C., Hisley, J., Kempler, T., 2000. What's everybody so excited about?: the effects of teacher enthusiasm on student intrinsic motivation and vitality. J. Exp. Educ. 68 (3), 217-236.

Petersen, A.C., Crockett, L., Richards, M., Boxer, A., 1988. A self-report measure of pubertal status: reliability, validity, and initial norms. J. Youth Adolesc. 17 (2), 117-133, http://dx.doi.org/10.1007/BF01537962.

Reeve, J., Tseng, C.-M., 2011. Cortisol reactivity to a teacher's motivating style: the biology of being controlled versus supporting autonomy. Motiv. Emot. 35 (1), 63-74, http://dx.doi.org/10.1007/s11031-011-9204-2.

Reeve, J., Jang, H., Carrell, D., Jeon, S., Barch, J., 2004. Enhancing students' engagement by increasing teachers' autonomy support. Motiv. Emot. 28 (2), 147-169, http://dx.doi.org/10.1023/B:MOEM.0000032312.95499.6f.

Rohleder, N., Nater, U.M., Wolf, J.M., Ehlert, U., Kirschbaum, C., 2004. Psychosocial stress-induced activation of salivary alpha-amylase: an indicator of sympathetic activity? Ann. N. Y. Acad. Sci. 1032 (1), 258-263, http://dx.doi.org 10.1196/annals.1314.033.

Ryan, R.M., Grolnick, W.S., 1986. Origins and pawns in the classroom: self-report and projective assessments of individual differences in children's perceptions. J. Pers. Soc. Psychol. 50 (3), 550-558.

Schüler, J., Sheldon, K.M., Fröhlich, S.M., 2010. Implicit need for achievement moderates the relationship between competence need satisfaction and subsequent motivation. J. Res. Pers. 44 (1), 1-12, http://dx.doi.org/10.1016/j. jrp.2009.09.002.

Schüler, J., Brandstätter, V., Sheldon, K.M., 2013. Do implicit motives and basic psychological needs interact to predict well-being and flow? Testing a universal hypothesis and a matching hypothesis. Motiv. Emot. 37 (3), 480-495 http://dx.doi.org/10.1007/s11031-012-9317-2.

Schüler, J., Sheldon, K.M., Prentice, M., Halusic, M., 2014. Do some people need autonomy more than others? Implicit dispositions toward autonomy moderate the effects of felt autonomy on well-being. J. Pers., http://dx.doi.org/ $10.1111 /$ jopy. 12133

Schoofs, D., Wolf, O.T., 2009. Stress and memory retrieval in women: no strong impairing effect during the luteal phase. Behav. Neurosci. 123 (3), 547-554, http://dx.doi.org/10.1037/a0015625.

Schultheiss, O.C., Köllner, M.G., 2014. Implicit motives, affect, and the development of competencies: a virtuous-circle model of motive-driven learning. In: Pekrun, R., Linnenbrink-Garcia, L. (Eds.), International Handbook of Emotions in Education. Taylor \& Francis/Routledge, New York, pp. 73-95.

Schultheiss, O.C., Pang, J.S., 2007. Measuring implicit motives. In: Robins, R.W., Fraley, R.C., Krueger, R. (Eds.), Handbook of Research Methods in Personality Psychology. Guilford, New York, pp. 322-344.
Schultheiss, O.C. 2008. Implicit motives. In: John, O.P., Robins, R.W., Pervin, L.A. (Eds.), Handbook of Personality: Theory and Research. Guilford, New York, pp. 603-633.

Schwartz, B., Ward, A., 2004. Doing better but feeling worse: the paradox of choice. In: Linley, P.A., Joseph, S. (Eds.), Positive Psychology in Practice. Wiley, Hoboken, N.J, pp. 86-104.

Schwartz, B., 2000. Self-determination: the tyranny of freedom. Am. Psychol. 55 (1), 79-88, http://dx.doi.org/10.1037//0003-066X.55.1.79.

Sheldon, K.M., Schüler, J., 2011. Wanting, having, and needing: integrating motive disposition theory and self-determination theory. J. Pers. Soc. Psychol. 101 (5), 1106-1123, http://dx.doi.org/10.1037/a0024952.

Skoluda, N., Strahler, J., Schlotz, W., Niederberger, L., Marques, S., Fischer, S., Thoma, M.V., Spoerri, C., Ehlert, U., Nater, U.M., 2015. Intra-individual psychological and physiological responses to acute laboratory stressors of different intensity. Psychoneuroendocrinology 51, 227-236, http://dx.doi.org/ 10.1016/j.psyneuen.2014.10.002

Strahler, J., Mueller, A., Rosenloecher, F., Kirschbaum, C., Rohleder, N., 2010. Salivary alpha-amylase stress reactivity across different age groups. Psychophysiology 47 (3), 587-595, http://dx.doi.org/10.1111/j.1469-8986. 2009.00957.x.

Strahler, J., 2012. Salivary alpha-amylase. In: Ehrlenspiel, F., Strahler, K. (Eds.), Psychoneuroendocrinology of Sport and Exercise. Routledge, New York, pp. 112-138.

Stroud, L.R., Foster, E., Papandonatos, G.D., Handwerger, K., Granger, D.A., Kivlighan, K.T., Niaura, R., 2009. Stress response and the adolescent transition: performance versus peer rejection stressors. Dev. Psychopathol. 21 (1), 47-68, http://dx.doi.org/10.1017/S0954579409000042.

Sumter, S.R., Bokhorst, C.L, Miers, A.C. van Pelt, J., Westenberg, P.M., 2010. Age and puberty differences in stress responses during a public speaking task: do adolescents grow more sensitive to social evaluation? Psychoneuroendocrinology 35 (10), 1510-1516, http://dx.doi.org/10.1016/j. psyneuen.2010.05.004.

van Stegeren, A., Rohleder, N., Everaerd, W., Wolf, O.T., 2006. Salivary alpha amylase as marker for adrenergic activity during stress: effect of betablockade. Psychoneuroendocrinology 31 (1), 137-141, http://dx.doi.org/10.1016/j. psyneuen.2005.05.012.

van den Bos, E., Rooij, M., de Miers, A.C., Bokhorst, C.L., Westenberg, P.M., 2014 Adolescents' increasing stress response to social evaluation: pubertal effects on cortisol and alpha-amylase during public speaking. Child Dev. 85 (1), 220-236, http://dx.doi.org/10.1111/cdev.12118.

Walker, E.L., Atkinson, J.W., 1958. The expression of fear related motivation in thematic apperception as a function of proximity to an atomic explosion. In: Atkinson, J.W. (Ed.), Motives in Fantasy, Action, and Society. Princeton, Van Nostrand, pp. 143-159.

Wegner, M., Schüler, J., Budde, H., 2014. The implicit affiliation motive moderates cortisol responses to acute psychosocial stress in high school students. Psychoneuroendocrinology 48, 162-168, http://dx.doi.org/10.1016/j. psyneuen.2014.06.013.

Williams, G.C., Grow, V., Freedman, Z.R., Ryan, R.M., Deci, E.L., 1996. Motivational predictors of weight loss and weight-loss maintenance. J. Pers. Soc. Psychol. 70 1), 115-126. 